\title{
Erratum to: Effectiveness of Pregabalin as Monotherapy or Combination Therapy for Neuropathic Pain in Patients Unresponsive to Previous Treatments in a Spanish Primary Care Setting
}

\author{
Emilio Blanco Tarrio • Rafael Gálvez Mateos • \\ Enric Zamorano Bayarri • Vanessa López Gómez • \\ Maria Pérez Páramo
}

Published online: 14 March 2014

(C) Springer International Publishing Switzerland 2014

\section{Clin Drug Investig (2013) 33:633-645 \\ DOI 10.1007/s40261-013-0116-7}

Page 644, Acknowledgments section which previously read

This study was sponsored by Pfizer SLU, Madrid, Spain. Statistical analysis was performed by the European Biometrics Institute and was funded by Pfizer SLU. Maria Pérez and Vanessa López Gómez were full-time employees of Pfizer SLU at the time of completion of the study and manuscript preparation. The others have no potential conflicts of interests that directly concern the content of this study.

\section{Should read}

This study was sponsored by Pfizer SLU, Madrid, Spain. The first draft of the manuscript was written by Almudena

The online version of the original article can be found under doi:10.1007/s40261-013-0116-7.

\footnotetext{
E. Blanco Tarrio

Centro de Salud de Béjar, Salamanca, Spain

R. Gálvez Mateos

Pain Unit, Hospital Virgen de las Nieves, Granada, Spain

E. Zamorano Bayarri

CAP Sant Antoni de Vilamajor, ABS Alt Mogent,

Barcelona, Spain

V. López Gómez · M. Pérez Páramo $(\bowtie)$

Medical Unit, Pfizer, Avda. de Europa, 20 B,

Parque Empresarial, La Moraleja, 28108 Alcobendas,

Madrid, Spain

e-mail: maria.perez2@pfizer.com
}

Pardo Mateos (Albiotech consultores, SL, Madrid, Spain) with funding provided by Pfizer SLU. Statistical analysis was performed by the European Biometrics Institute and was funded by Pfizer SLU. Maria Pérez and Vanessa López Gómez were full-time employees of Pfizer SLU at the time of completion of the study and manuscript preparation. The others have no potential conflicts of interests that directly concern the content of this study. 